\title{
DISTRIBUTION OF SODIUM BICARBONATE INFUSED INTO NEPHRECTOMIZED DOGS ${ }^{1}$
}

\author{
By ROY C. SWAN,? DAVID R. AXELROD, MURIEL SEIP, AND ROBERT F. PITTS \\ WITH THE TECHNICAL ASSISTANCE OF HARRY MADISSO
}

(From the Department of Physiology, Cornell University Medical College, Nea' York, N. Y.)

(Submitted for publication July 7, 1955; accepted August 10, 1955)

The participation of intracellular buffers in stabilizing hydrogen ion concentration in body fluids (1) is suggested by studies in which mineral acid has been administered at rates in excess of renal excretion of acid (2-4). Neutralization as bicarbonate of retained carbon dioxide (5-8) also indicates the role of intracellular buffers when acid loading overwhelms respiratory and renal regulations of acid-base equilibrium. While intracellular buffers might be expected to participate in neutralizing excess alkali, studies of the distribution of administered bicarbonate in cat muscle (9) and in the whole body of man (10) do not allocate to intracellular buffers a significant role in neutralizing administered alkali.

The extent to which blood and tissue buffers participate in neutralizing alkali infused as sodium bicarbonate has been studied by measuring changes in the total quantity of extracellular and erythrocyte sodium, potassium, bicarbonate, and chloride following infusion of sodium bicarbonate into nephrectomized dogs. Preliminary reports (11, 12) were based on experiments in which extracellular fluid volume was approximated by inulin distribution. Subsequent studies in this laboratory indicated that radiosulfate distribution more closely approximates extracellular fluid volume in the whole animal than does inulin distribution (13). Therefore these studies have been repeated using radiosulfate distribution to measure changes in extracellular fluid volume. No definitive publication of the original experiments is contemplated.

The results of our recent experiments indicate that when $20 \mathrm{mM}$ of sodium bicarbonate per kilogram of body weight are infused into a nephrectomized dog over a period of two and a half hours,

\footnotetext{
1 Supported by a grant from the American Heart Association.

2 Present address: Physiological Laboratory, Cambridge, England.
}

three-fourths of the added sodium and two-thirds of the added bicarbonate remain in extracellular fluid, while one-fourth of the added sodium probably exchanges for intracellular hydrogen ion.

\section{EXPERIMENTAL PLAN}

Dogs were nephrectomized immediately before each experiment to eliminate renal excretion of water and ions and to permit more accurate measurement of the volume of distribution of radiosulfate. Control values for sodium, potassium, bicarbonate, and chloride in extracellular fluid and in the circulating erythrocyte mass were established three and four hours after nephrectomy. One and two hours after the production of severe metabolic alkalosis by infusion of sodium bicarbonate ( 0.6 normal in the first group of four experiments, 0.3 normal in the second group of four experiments) the total amounts of each of these ions in extracellular fluid and in the erythrocyte mass were re-established. Ion transfers to and from extracellular fluid and into and out of circulating erythrocytes were calculated from the differences in mean ion contents observed in the two control and two alkalosis observations. Results of four control experiments performed under comparable conditions have been reported previously (4).

\section{EXPERIMENTTAL PROCEDURE}

Healthy, moderately lean, adult male dogs were lightly anesthetized with sodium pentobarbital, weighed and nephrectomized bilaterally. Radiosulfate $\left(\mathrm{S}^{35} \mathrm{O}_{4}\right)$ and (in three of eight experiments) radiochloride $\left(\mathrm{Cl}^{36}\right)$ were infused as previously described (13). Two and one-half, three, three and one-half and four hours after infusion of radioisotopes arterial blood samples were drawn for measurement of plasma radiosulfate concentration and plasma specific gravity. Additional samples were obtained at three and four hours for measurement of plasma and whole blood sodium, potassium, $\mathrm{CO}_{2}$, chloride, and for plasma radiochloride concentrations, plasma $\mathrm{pH}$ whole blood water content, hematocrit and, in the second group of experiments, for plasma inorganic phosphate concentration.

Following the four-hour blood sampling sodium bicarbonate was infused through a polyethylene catheter inserted through a femoral vein into the inferior vena cava. In the first group, 0.6 normal sodium bicarbonate was infused at $4 \mathrm{ml}$. per minute. In the second group 0.3 nor- 
mal sodium bicarbonate was infused at $8 \mathrm{ml}$. per minute. A total of approximately $20 \mathrm{mM}$ per $\mathrm{Kg}$. of body weight was infused in each experiment. Sodium bicarbonate solutions were equilibrated with 5 to 7 per cent $\mathrm{CO}_{2}$ before infusion to reduce alkalinity.

One hour following completion of the infusion of sodium bicarbonate and at half-hour intervals thereafter, four arterial blood samples were drawn for re-measurement of all plasma and whole blood components. Plasma volume was measured by $\mathrm{T}-1824$ dilution one and one-half hours before the infusion of sodium bicarbonate was started and one and one-half hours after the infusion was completed.

Approximately $120 \mathrm{ml}$. of blood were drawn before and a similar amount following the infusion. Autopsy following each experiment verified that renal excretion had been completely eliminated and that hemorrhage at the operative sites had not occurred.

\section{ANALYTICAL METHODS AND CALCULATIONS}

The analytical methods used and the methods of calculating results have been described previously (4). The ratio of concentrations of chloride in erythrocyte and plasma water averaged 0.64 in control periods and 0.61 after infusion of sodium bicarbonate.

Since this study was completed the distribution of radiosulfate across cellophane membranes between plasma and an ultrafiltrate of plasma has been studied in this laboratory and indicates a Donnan factor for sulfate of 0.96 (4), rather than 0.90 previously assumed. The measurement of erythrocyte penetration by radiosulfate under comparable experimental conditions indicates an additional small correction should be applied in calculating radiosulfate volumes (14). This latter correction in large part cancels the increase in volume of distribu- tion obtained by using the observed, rather than the assumed, Donnan factor for the sulfate ion. Recalculation of the results of the experiments reported herein using a Donnan factor of 0.96 and correcting for penetration of erythrocytes by radiosulfate does not significantly alter results described below.

\section{RESULTS}

In the first group of four experiments the combination of marked alkalosis and marked hypertonicity of body fluids induced by infusing 0.6 normal sodium bicarbonate was poorly tolerated. Varying degrees of tetany, tachypnea, hyperthermia, hypoxia and hypotension developed which may underly the inconstant changes in extracellular ion content observed in this group of experiments as compared to the second group. In the second group of four experiments the infusion of 0.3 normal sodium bicarbonate was well tolerated.

Detailed data from an experiment representative of the first group of experiments are presented in Table I. The infusion of $390 \mathrm{mM}$ of sodium bicarbonate into a $19.9 \mathrm{Kg}$. dog raised the plasma $\mathrm{pH}$ from 7.43 to 7.67 , the concentration of sodium in plasma water from $152 \mathrm{mM}$ per liter to 180 $\mathrm{mM}$ per liter, the concentration of bicarbonate from $26 \mathrm{mM}$ per liter to $59 \mathrm{mM}$ per liter and reduced the concentrations of potassium and chloride. The increment in the radiosulfate volume exceeds the volume of hypertonic sodium bicarbo-

TABLE I

Aicrage changes in total millimols of each monozalcnt ion in cxtracellular fluid and in circulating erythrocytc mass derived from z'olumes and concentrations measured in an experiment represcntative of the first group of experiments

\begin{tabular}{|c|c|c|c|c|c|c|c|c|c|c|c|c|c|c|c|c|c|}
\hline & Plasma & $\mathrm{S}^{35} \mathrm{O}_{4}$ & Hemat & Plasma & Conc. & in $\mathrm{Pl}$ & losmo & Water & & Etrac & ellular & & Conc & c. in & Erythr & trocyte & \\
\hline Time & Water & Vol. & -ocrit & $\mathrm{pH}$ & No & $k$ & $\mathrm{HCO}_{3}$ & $\mathrm{Cl}$ & No & $\bar{K}$ & $\mathrm{HCO}_{3}$ & $\mathrm{Cl}$ & No & $K$ & $\mathrm{HCO}_{3}$ & 3 & $\mathrm{H}_{2} \mathrm{O}$ \\
\hline hours & $\mathrm{ml}$. & $\mathrm{ml}$. & & & & illimo & ols per & liter & & ol $\mathrm{m}$ & illimols & & & illimols & s per & liter & $\%$ \\
\hline 3.00 & 900 & 4355 & 430 & 7.43 & 151.9 & 5.1 & 25.5 & 113.8 & 635 & 21 & 115 & 516 & 103 & 7.4 & 10.2 & 45.4 & 621 \\
\hline 4.00 & & & .440 & 7.43 & 152.8 & 5.5 & 25.5 & 113.8 & 640 & 23 & 115 & 516 & 96 & 7.3 & 10.2 & 46.2 & 62.0 \\
\hline 4.16 & -6.50 & & Infusi & on of & 650 & $\mathrm{ml}$. & of 0 & .5961 & N Noh & $\mathrm{ACO}_{3}$ & 1390 & $\mathrm{mM}$ & ). 19. & $9 \mathrm{Kg}$ & Dog & & \\
\hline 7.50 & 900 & 5045 & 440 & 7.68 & 179.0 & 3.4 & 59.6 & 94.8 & 866 & 17 & 314 & 500 & 130 & 6.7 & 21.3 & 34.1 & 60.9 \\
\hline 8.50 & & & .435 & 7.66 & 180.0 & 3.4 & 58.2 & 95.7 & 870 & 16 & 306 & 502 & 129 & 6.4 & 20.8 & 33.8 & 60.7 \\
\hline & & & Aver & ge Ch & hange & ( total & II milli & nols) & +230 & -5 & +195 & -15 & +22 & +0.7 & +8 & -9 & \\
\hline
\end{tabular}


TABLE II

Average changes in total millimols of each monovalent ion in extracellular fluid and in circulating erythrocyte mass derived from volumes and concentrations measured in an experiment representative of the second group of experiments

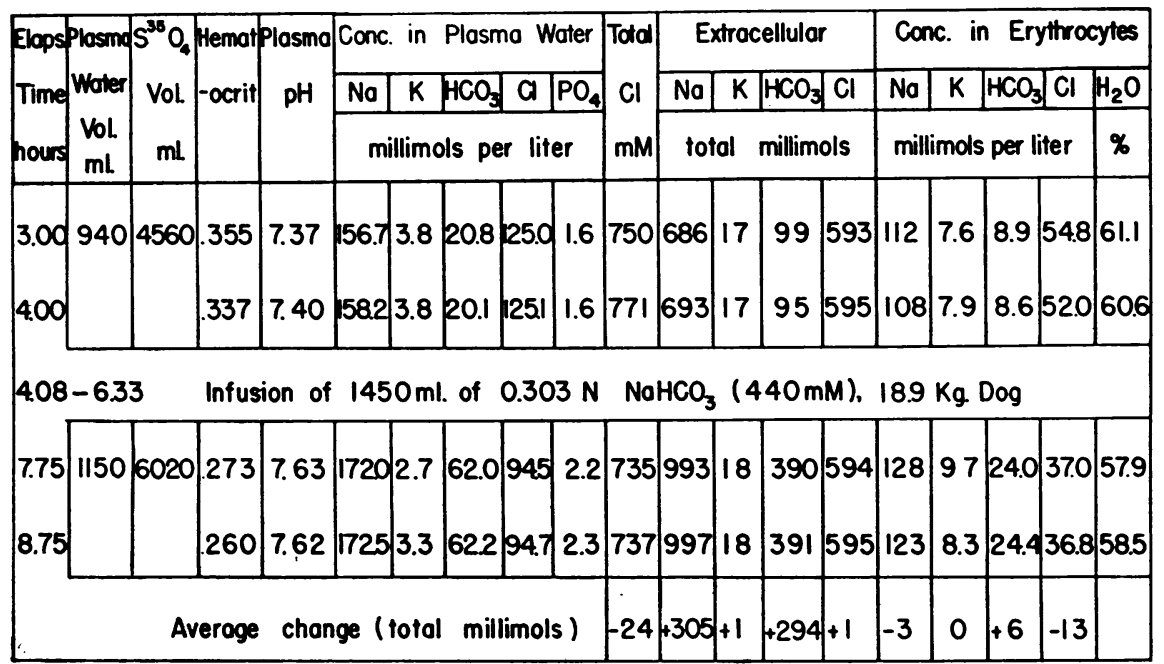

nate infused. Total extracellular sodium increased $230 \mathrm{mM}$, bicarbonate increased $195 \mathrm{mM}$, while extracellular potassium and chloride decreased 5 and $15 \mathrm{mM}$, respectively. Total sodium and bicarbonate in circulating erythrocytes increased 22 and $8 \mathrm{mM}$, respectively, while chloride decreased $9 \mathrm{mM}$.

Detailed data from a representative experiment in the second group are presented in Table II. The infusion of $440 \mathrm{mM}$ of sodium bicarbonate into an $18.9 \mathrm{Kg}$. dog raised the plasma $\mathrm{pH}$ from 7.38 to 7.63 , the concentration of sodium in plasma water from 157 to $172 \mathrm{mM}$ per liter, the concentration of bicarbonate from 20 to $62 \mathrm{mM}$ per liter, the concentration of phosphate from 1.6 to $2.3 \mathrm{mM}$ per liter and reduced the concentration of potas-

TABLE III

Summary of data from the eight experiments

\begin{tabular}{|c|c|c|c|c|c|c|c|c|c|c|c|c|c|c|c|c|c|}
\hline \multirow{3}{*}{$\begin{array}{l}\text { Exp. } \\
\text { No. }\end{array}$} & \multirow{3}{*}{$\begin{array}{l}\mathbf{W t} . \\
\mathrm{Kg} .\end{array}$} & \multicolumn{2}{|c|}{$\mathrm{NaHCO}_{3}$} & Infused & \multirow{3}{*}{$\begin{array}{c}\Delta \\
\text { Total } \\
\mathrm{Cl} \\
\mathrm{mM} \\
\end{array}$} & \multirow{3}{*}{$\begin{array}{c}\Delta \\
\mathrm{S}^{35} \mathrm{O}_{4} \\
\text { Vol. } \\
\mathrm{ml} .\end{array}$} & \multirow{3}{*}{$\begin{array}{l}\text { Find } \\
\text { Plosmo } \\
\mathrm{pH}\end{array}$} & \multicolumn{4}{|c|}{$\begin{array}{c}\Delta \text { Conc. in } \\
\text { Plosmo Water }\end{array}$} & \multicolumn{4}{|c|}{$\begin{array}{l}\Delta \text { Total } \\
\text { Extracellular }\end{array}$} & \multirow{2}{*}{\multicolumn{2}{|c|}{$\begin{array}{c}\% \text { Infused } \\
\text { Lost From } \\
\text { ECF }\end{array}$}} \\
\hline & & Totd & $\mathrm{mM} /$ & Vol. & & & & No & $\mathrm{K}$ & $\mathrm{HCO}_{3}$ & $\mathrm{Cl}$ & $\mathrm{Na}$ & $k$ & $\mathrm{HCO}_{3}$ & $\mathrm{Cl}$ & & \\
\hline & & $\mathrm{mM}$ & $/ \mathrm{kg}$ & $\mathrm{ml}$. & & & & \multicolumn{2}{|c|}{ millimols } & per 1 & liter & \multicolumn{4}{|c|}{ millimols } & $\mathrm{Na}$ & $\mathrm{HCO}_{3}$ \\
\hline 1 & 187 & 330 & 17.6 & 550 & & +740 & 7.55 & +25 & +0.4 & +33 & -22 & +211 & +4 & +200 & -6 & 26 & 39 \\
\hline 2 & 26.9 & 495 & 18.4 & 825 & & +1815 & 7.60 & +27 & -0.3 & +32 & -19 & +463 & +7 & +282 & +94 & 10 & 43 \\
\hline 3 & 20.9 & 387 & 18.5 & 650 & & +1213 & 7.60 & +28 & +0.8 & +37 & $|-21|$ & +309 & +8 & +218 & +42 & 20 & 44 \\
\hline 4 & 19.9 & 390 & 19.6 & 650 & & +690 & 7.67 & +28 & -1.9 & +33 & -19 & +230 & -5 & +195 & -15 & 31 & 50 \\
\hline Av. & 21.6 & 401 & 18.5 & 669 & & +11114 & & +27 & -0.3 & +34 & -20 & +303 & +4 & +224 & +29 & 24 & 44 \\
\hline 5 & 20.5 & 392 & 19.1 & 1305 & +4 & 4515 & 7.59 & +18 & -0.6 & +35 & -23 & +335 & +2 & +278 & +26 & 15 & 29 \\
\hline 6 & 17.5 & 330 & 18.9 & 1100 & -7 & +1225 & 7.69 & +15 & -0.7 & +38 & -28 & +250 & +2 & $+231 \mid$ & +5 & 24 & 30 \\
\hline 7 & 18.9 & 440 & 23.2 & 1450 & -24 & .1460 & 7.63 & +15 & -0.8 & +42 & -30 & +305 & +1 & +294 & +1 & 31 & 33 \\
\hline 8. & 293 & 585 & 20.0 & 1950 & & +1980 & 7.68 & +14 & -0.3 & +39 & -32 & +398 & .6 & +350 & +2 & 32 & 40 \\
\hline Av. & 21.6 & 437 & 20.3 & 1450 & & 2040 & & +16 & [- 0.0 & +39 & -28 & poce & +3 & +288 & +9 & 26 & 34 \\
\hline
\end{tabular}


sium and chloride. The increase in radiosulfate volume exceeds slightly the volume of the infusion. Total extracellular sodium increased 305 $\mathrm{mM}$, bicarbonate increased $294 \mathrm{mM}$, while total extracellular potassium and chloride remained essentially unchanged. Total circulating erythrocyte chloride decreased as erythrocyte bicarbonate increased.

In Table III are summarized the results of the four experiments in each of the two groups. In the first group the four animals, averaging 21.6 $\mathrm{Kg}$., received an average of $18.5 \mathrm{mM}$ of sodium bicarbonate per $\mathrm{Kg}$. of body weight. Extracellular fluid volume, as measured by radiosulfate distribution, averaged initially 20.1 per cent of body weight and increased an average of $1114 \mathrm{ml}$. following infusion of $669 \mathrm{ml}$. of approximately 0.6 normal sodium bicarbonate. Total sodium in extracellular fluid increased $303 \mathrm{mM}$. equivalent to 76 per cent of the sodium infused. Total extracellular potassium increased $4 \mathrm{mM}$. Total bicarbonate increased $224 \mathrm{mM}$, equivalent to 56 per cent of infused bicarbonate. The change in total chlo-

TABLE IV

Change in osmolarity of plasma water due to monozalent ions and change in anion deficit of plasma a'ater following infusion of sodium bicarbonate

\begin{tabular}{|c|c|c|c|c|}
\hline \multirow{2}{*}{$\begin{array}{c}\text { Exp. } \\
\text { No. }\end{array}$} & \multicolumn{2}{|c|}{ Milliosmols per liter } & \multicolumn{2}{c|}{ Anion Deficit (mEq./L) } \\
\hline Before $\mathrm{NaHCO}_{3}$ & After $\mathrm{NaHCO}_{3}$ & \multicolumn{2}{c|}{ Before $\mathrm{NaHCO}_{3}$} & After $\mathrm{NaHCO}_{3}$ \\
\hline 1 & 297.6 & 342.8 & 25.0 & 29.0 \\
2 & 306.5 & 347.7 & 20.9 & 34.5 \\
3 & 294.1 & 339.7 & 18.9 & 31.7 \\
4 & 297.0 & 337.3 & 18.4 & 28.5 \\
\hline Av. & 298.8 & 341.9 & 20.8 & 31.1 \\
\hline & & & & \\
\hline 5 & 298.2 & 324.3 & 14.7 & 17.4 \\
\hline 6 & 298.1 & 321.9 & 16.5 & 20.2 \\
\hline 7 & 306.3 & 332.0 & 15.8 & 18.6 \\
\hline 8 & 302.0 & 323.4 & 18.4 & 24.3 \\
\hline Av. & 301.1 & 325.4 & 16.4 & 20.1 \\
\hline
\end{tabular}

ride was quite variable, the average increase being equivalent to 7 per cent of the infused bicarbonate.

In the second group of experiments the four animals, averaging $21.6 \mathrm{Kg}$., received an average of $20.3 \mathrm{mM}$ of sodium bicarbonate per $\mathrm{Kg}$. of body weight. Extracellular fluid volume, averaging initially 22.6 per cent of body weight, increased an average of $1,545 \mathrm{ml}$. following infusion of 1,450 ml. of approximately 0.3 normal sodium bicarbonate. Total sodium in extracellular fluid in creased $322 \mathrm{mMI}$, equivalent to 74 per cent of infused sodium. Total potassium increased $3 \mathrm{mM}$. Total bicarbonate increased $288 \mathrm{mM}$, equivalent $\mathrm{t}^{\circ}$ 66 per cent of infused bicarbonate, while total chloride increased $9 \mathrm{mM}$, a change equivalent to only 2 per cent of infused sodium bicarbonate. Total exchangeable chloride (not given in Table III) was $753 \mathrm{mM} .599 \mathrm{mM}$ and $760 \mathrm{mM}$ in experiments 5.6 and 7 , respectively, averaging 37 $\mathrm{m} M I$ chloricle per $\mathrm{Kg}$. of body weight. Total exchangeable chloride increased $4 \mathrm{mM}$ in Experiment 5. decreased $7 \mathrm{mM}$ and $24 \mathrm{mM}$ in Experiments 6 and 7 . respectively. decreasing on an average only 1 per cent. a change which is not significant. The average change in total extracellular chloricle of $9 \mathrm{mM}$ therefore represents an increase equivalent to only 1 per cent of total body chloricle.

In the first group of experiments the change in total sodium, potassium. bicarbonate. and chloricle in circulating erythrocytes after sodium bicarbonate infusion averaged $+18 \mathrm{mM}$ (range for the four experiments, +16 to +22$), 0 \mathrm{mM}$ $(+0.6$ to -0.7$),+10 \mathrm{mM}(+8$ to +13$)$ and $-6 \mathrm{mMI}(-+$ to $-9 \mathrm{mM})$, respectively. In the second group of experiments these changes averaged $-13(-3$ to -20$)$ for sodium, $-1(-0.2$ to -2.9$)$ for potassium, $+4(+2.1$ to 5.9$)$ for bicarbonate, and -17 ( -13 to -24$)$ for chloride. Changes in concentrations of these ions in erythrocytes are consistent in the two groups of experiments as is apparent in Table I and II. The difference in results between the two groups of experiments as regards total ion content of circulating erythrocytes is apparently due to loss of circulating erythrocytes or to underestimation of plasma volume following sodium bicarbonate infusion in the second group of experiments. Reasons for either of these two possibilities are not apparent. Sources of error in these measurements of changes in ion content of circulating erythro- 
cytes have been discussed by Giebisch, Berger, and Pitts (8).

Table IV summarizes changes in osmolarity of plasma water contributed by the four monovalent ions, sodium, potassium, bicarbonate, and chloride and changes in anion deficit $(\mathrm{Na}+\mathrm{K}-$ $\mathrm{HCO}_{3}-\mathrm{Cl}$ ) resulting from the infusion of sodium bicarbonate. Osmolarity increased 43.1 mOsm. per liter in the first group of experiments and $24.3 \mathrm{mOsm}$. per liter in the second group. The difference between monovalent cations ( $\mathrm{Na}$ plus $\mathrm{K})$ and monovalent anions $\left(\mathrm{HCO}_{3}\right.$ plus $\left.\mathrm{Cl}\right)$ increased $10.3 \mathrm{mEq}$. per liter and $3.7 \mathrm{mEq}$. per liter in the first and second group of experiments, respectively.

In the first group of experiments the calculated increase in anion equivalence of plasma protein with rising $\mathrm{pH}$ is largely offset by the decrease in concentration of plasma protein following sodium bicarbonate infusion. Anions other than those analyzed for have accumulated apparently in extracellular fluid. In the second group of experiments the decrease in plasma protein concentration following infusion exceeded by $2.3 \mathrm{mEq}$. per liter the increase in anion equivalence expected from increasing $\mathrm{pH}$. Plasma inorganic phosphate concentration increased an average of $0.4 \mathrm{mEq}$. per liter in this group of experiments. Thus approximately $5.6(3.7+2.3-0.4) \mathrm{mEq}$. per liter of undetermined anion has appeared in plasma following infusion of sodium bicarbonate.

Changes in ion content of circulating erythrocytes and in osmolarity of plasma water contributed by monovalent ions observed in control experiments under comparable conditions have been previously reported (4).

\section{DISCUSSION}

These results indicate that in the nephrectomized dog three-fourths of the sodium and twothirds of the bicarbonate infused as sodium bicarbonate remain in extracellular fluid as measured by radiosulfate distribution. In contrast to earlier reports by us (1) and others (15) of studies based on inulin distribution total extracellular chloride increases only slightly and by an amount approximating the measured decrement in chloride of circulating erythrocytes.

The marked increase in carbonic acid concen- tration and $\mathrm{pCO}_{2}$ of plasma which can be calculated from data of Tables I and II represents respiratory regulation of extracellular hydrogen ion concentration. Without this retention of $\mathrm{CO}_{2}$ hydrogen ion concentration would fall far below limits for survival.

\section{Accumulation of unmeasured anion in extracel- lular fluid}

The fraction of infused bicarbonate disappearing from extracellular fluid exceeds considerably the fraction of infused sodium disappearing from extracellular fluid. From Table IV this apparently results largely from accumulation of unmeasured anion displacing bicarbonate in extracellular fluid to the extent of $5.6 \mathrm{mEq}$. per liter in the second group of experiments, to a slightly greater extent in the first group of experiments. This anion is probably mostly lactate. Increase in plasma lactate concentration of this magnitude in alkalosis of this degree but of respiratory origin has been observed under comparable experimental conditions by Giebisch, Berger, and Pitts (8) and in metabolic alkalosis by others (16). Regarded earlier as compensatory (17) or the result of tissue hypoxia (18) lactate accumulation may be a more direct effect of alkalosis on carbohydrate metabolism (19).

Fate of fraction of infused sodium leaving extracellular fluid

The fate of the 25 per cent of infused sodium leaving extracellular fluid and of an equivalent amount of bicarbonate is not shown by these experiments. The magnitude of this fraction is in close agreement with that observed by Singer, Clark, Barker, Crosley, and Elkinton (20) despite great difference in degree of alkalosis and in experimental conditions. These investigators infused $2.4 \mathrm{mEq}$. sodium bicarbonate per $\mathrm{Kg}$. of body weight into normal man over a ten-minute period and observed for one and one-half to two hours changes in concentrations of ions in plasma and change in volume of extracellular fluid as measured by chloride distribution.

When the distribution of sodium bicarbonate in our experiments is calculated on the basis of radiochloride distribution (13), as can be done in the experiments (No. 5, 6, 7) in which total body 
TABLE $V$

Average changes in total millimols of each monovalent ion in extracellular fluid when the volume of the latter is measured by radiochloride distribution*

\begin{tabular}{|c|c|c|c|c|c|c|c|c|c|}
\hline \multirow{3}{*}{$\begin{array}{l}\text { Exp. } \\
\text { No }\end{array}$} & \multirow{3}{*}{$\begin{array}{l}\text { Plasma } \\
\text { Vol. } \\
\text { MI. }\end{array}$} & \multirow{3}{*}{$\begin{array}{c}\text { Chloride } \\
\text { Vol. } \\
\text { MI. }\end{array}$} & \multicolumn{2}{|c|}{$\mathrm{RBCNaHCO}$} & \multicolumn{4}{|c|}{$\begin{array}{l}\Delta \text { Total } \\
\text { Extracellular }\end{array}$} & \multirow{3}{*}{$\frac{\mathrm{Cl} \mathrm{Vol} . \mathrm{S}}{\mathrm{S}^{35} \mathrm{O}_{4} \mathrm{Vol}}$} \\
\hline & & & \multirow{2}{*}{$\begin{array}{c}\mathrm{Cl} \\
\mathrm{mM}\end{array}$} & \multirow{2}{*}{$\begin{array}{c}\text { Given } \\
\mathrm{mM}\end{array}$} & $\mathrm{Na}$ & $\mathrm{K}$ & $\mathrm{HCO}_{3}$ & $\mathrm{Cl}$ & \\
\hline & & & & & \multicolumn{4}{|c|}{ millimols } & \\
\hline \multirow{2}{*}{5} & 1180 & 5820 & 30 & \multirow{2}{*}{392} & \multirow{2}{*}{\multicolumn{2}{|c|}{$+352 \mid+$}} & \multirow{2}{*}{+303} & \multirow{2}{*}{+17} & 1.14 \\
\hline & 1085 & 7355 & 17 & & & & & & 1.12 \\
\hline \multirow{2}{*}{6} & 770 & 4515 & 33 & \multirow{2}{*}{330} & \multirow{2}{*}{+301} & \multirow{2}{*}{+2} & \multirow{2}{*}{+271} & \multirow{2}{*}{+12} & 1.16 \\
\hline & 900 & 6000 & 13 & & & & & & 1.17 \\
\hline \multirow{2}{*}{7} & 940 & 5600 & 29 & \multirow{2}{*}{440} & \multirow{2}{*}{+402} & \multirow{2}{*}{+1} & \multirow{2}{*}{+408} & \multirow[t]{2}{*}{-21} & 1.23 \\
\hline & 1150 & 7280 & 16 & & & & & & 1.21 \\
\hline Av. & & & & 387 & +352 & +2 & +327 & +3 & $\begin{array}{l}1.18 \\
1.17\end{array}$ \\
\hline
\end{tabular}

* Where two values are given for each experiment the upper value represents the control period; the value underneath represents the period following sodium bicarbonate infusion.

chloride was measured, a somewhat different distribution is apparent (Table V). The initial ratio of chloride volume to radiosulfate volume is in agreement with that previously calculated (13) and remains unchanged after infusion. Since the chloride volume exceeds the sulfate volume, the fraction of infused sodium and bicarbonate not accounted for in the chloride volume is smaller ( 9 per cent and 15 per cent, respectively). Reasons for considering that radiosulfate distribution is a better measure of extracellular fluid volume than is chloride distribution have been summarized previously (13).

The fraction of infused sodium bicarbonate not accounted for in extracellular fluid may 1) diffuse into cells, increasing intracellular sodium and bicarbonate accordingly, 2) may be neutralized by intracellular buffers, hydrogen ion derived from cell buffers exchanging with sodium and reacting with bicarbonate to form $\mathrm{CO}_{2}$ and water or 3 ) may be neutralized by ion exchange at surfaces of extracellular solid structures $(21,22)$. These possibilities have been discussed by Singer, Clark. Barker, Crosley, and Elkinton (20).

Regarding possibility 1, Wallace and Hastings (9) calculated that intracellular bicarbonate concentration in muscle remains constant as extracellular bicarbonate concentration increases. The validity of this calculation is in some doubt (23) and from application of Donnan theory to ionic equilibria across cell membranes (24) intracellular bicarbonate concentration would be expected to increase as $\mathrm{pCO}_{2}$ and extracellular bicarbonate concentration increase.

Possibility 2 and 3 entail loss from body fluids of infused ions. The observed increase in osmolarity of body fluids might be expected to be less than in the case of possibility 1 . The expected change in osmolarity of plasma contributed by monovalent ions and change in extracellular fluid volume can be calculated (4) by assuming a) an initial body water of 60 per cent of body weight. b) osmotic equilibrium between cells and extracellular fluid, c) a small insensible water loss of about $75 \mathrm{ml}$. between the control period and the period of alkalosis and $d$ ) that the accumulating unmeasured anion is lactate. The observed increase in osmolarity of plasma water contributed by monovalent ions is less than that expected on the basis of possibility 1 , and is in fair agreement with that expected on the basis of possibilities 2 and 3. However, the assumptions are large and the possible error of such calculations too great to distinguish between possibility 2 and 3 or to support the distribution of sodium bicarbonate as revealed by either radiosulfate or radiochloride distribution over that revealed by the distribution of the other.

The implications of the observed distribution of infused sodium bicarbonate in treating metabolic acidosis have been discussed by others (20)

\section{SLMMARY}

Sodium bicarbonate, totalling $20 \mathrm{mM}$ per $\mathrm{Kg}$. of body weight, has been infused into nephrectomized dogs and its distribution studied with respect to the measured volume of extracellular fluid. Three-fourths of the infused sodium bicarbonate remains in extracellular fluid. Some of this extracellular fraction is subsequently neutralized by accumulating acid, probably lactic. The remaining one-fourth of the infused sodium bicarbonate leaves extracellular fluid and may be neutralized as sodium exchanges for hydrogen ion derived from intracellular buffers.

\section{REFERENCES}

1. Pitts, R. F., Mechanisms for stabilizing the alkaline reserves of the body. Harvey Lectures, 1952-53. 48, 172. 
2. Van Slyke, D. D., and Cullen, G. E., Studies of acidosis. I. The bicarbonate concentration of the blood plasma; its significance and its determination as a measure of acidosis. J. Biol. Chem., 1917, 30, 289.

3. Schwartz, W. B., Jenson, R. L., and Relman, A. S., The disposition of acid administered to sodiumdepleted subjects: The renal response and the role of the whole body buffers. J. Clin. Invest., 1954, 33, 587.

4. Swan, R. C., and Pitts, R. F., Neutralization of infused acid by nephrectomized dogs. J. Clin. Invest., 1955, 34, 205.

5. Shaw, L. A., The comparative capacity of the blood and the tissue to absorb carbonic acid. Am. J. Physiol., 1926, 79, 91.

6. Adolph, E. F., Nance, F. D., and Shiling, M. S., The carbon dioxide capacity of the human body and the progressive effects of carbon dioxide upon breathing. Am. J. Physiol., 1929, 87, 532.

7. Irving, L., Ferguson, J. K. W., and Plewes, F. B., The source of $\mathrm{CO}_{2}$ expired and the site of its retention. J. Physiol., 1930, 69, 113.

8. Giebisch, G., Berger, L., and Pitts, R. F., The extrarenal response to acute acid-base disturbances of respiratory origin. J. Clin. Invest., 1955, 34, 231.

9. Wallace, W. M., and Hastings, A. B., The distribution of the bicarbonate ion in mammalian muscle. J. Biol. Chem., 1942, 144, 637.

10. Rosenbaum, J. D., The influence of alterations in acid-base balance upon transfers of carbon dioxide and bicarbonate in man. J. Clin. Invest., 1942, 21, 735.

11. Pitts, R. F., and Axelrod, D. R., Chloride bicarbonate shift in body cells. Am. J. Physiol., 1952, 171, 757 (abstract).

12. Pitts, R. F., Fourth Conference on Renal Function, 1952, Bradley, S. E., Ed., New York, Josiah Macy, Jr. Foundation, 1953, p. 11.

13. Swan, R. C., Madisso, H., and Pitts, R. F., Measurement of extracellular fluid volume in nephrectomized dogs. J. Clin. Invest., 1954, 33, 1447.
14. Swan, R. C., Feinstein, H. M., and Madisso, H., Distribution of the sulfate ion across capillary and erythrocyte membranes. (Submitted for publication).

15. Roberts, K. E., Randall, H. T., Philbin, P., and Lipton, R., Changes in extracellular water and electrolytes and the renal compensations in chronic alkalosis, as compared to those occurring in acute alkalosis. Surgery, 1954, 36, 599.

16. MacLeod, J. J. R., and Hoover, D. H., Studies in experimental glycosuria. XII. Lactic acid production in the blood following the injection of alkaline solutions of dextrose or of alkaline solutions alone. Am. J. Physiol., 1917, 42, 460.

17. Anrep, G. V., and Cannan, R. K., The concentration of lactic acid in the blood in experimental alkalæmia and acidoæmia. J. Physiol., 1923, 58, 244.

18. Peters, J. P., and Van Slyke, D. D., Quantitative Clinical Chemistry, Volume I, Interpretations, Baltimore, Williams \& Wilkins, 1931, p. 476.

19. Katzman, R., Villee, C. A., and Beecher, H. K., Effect of increased carbon dioxide concentrations on fixed acid production in vitro. Am. J. Physiol., 1953, 172, 317.

20. Singer, R. B., Clark, J. K., Barker, E. S., Crosley, A. P., Jr., and Elkinton, J. R., The acute effects in man of rapid intravenous infusion of hypertonic sodium bicarbonate solution. I. Changes in acidbase balance and distribution of the excess buffer base. Medicine, 1955, 34, 51.

21. Bergstrom, W. H., and Wallace, W. M., Bone as a sodium and potassium reservoir. J. Clin. Invest., 1954, 33, 867.

22. Neuman, W. F., Toribara, T. Y., and Underwood, A. L., State of carbonate in bone mineral. Federation Proc., 1955, 14, 260.

23. Wallace, W., Fourth Conference on Renal Function, 1952, Bradley, S. E., Ed., New York, Josiah Macy, Jr. Foundation, 1953, p. 48.

24. Conway, E. J., The physiological significance of inorganic levels in the internal medium of animals. Biol. Rev., 1945, 20, 56. 